\title{
La 'llave del recuerdo' y los anómalos relatos de metamorfosis en The legend of Good Women de Geoffrey Chaucer
}

\author{
Maria Cristina Balestrini \\ Facultad de Filosofía y Letras, Universidad de Buenos Aires, \\ Argentina \\ cristinabalestrini@gmail.com
}

\section{Resumen:}

The Legend of Good Women Chaucer empuja las formas literarias recibidas hacia un terreno experimental pendiente a la vez de la tradición y de sus renovados efectos. En coincidencia con otros textos del autor, se ofrece una reelaboración de historias procedentes de Ovidio a partir de una apropiación deliberadamente fragmentada que se nota particularmente en un uso anómalo de la metamorfosis como tópico narrativo. La escritura funciona en este poema como clave para acceder a una memoria cultural compartida más que como despliegue de erudición o búsqueda de verdades subyacentes.

Palabras Clave: Chaucer, Legend of Good Women, Metamorfosis, Memoria.

\section{ABSTRACT:}

The Legend of Good Women pushes received literary forms into an experimental ground focusing at the same time on tradition and on in its renewed effects. In accordance with other texts by the author, this poem offers a rewriting of Ovidian stories through a deliberately scattered appropriation particularly observable in its anomalous use of metamorphosis as a narrative topic. In this poem, writing serves as the key to a shared cultural memory, instead of making a display of learning or of disclosing underlying truths.

KEYWORDS: Chaucer, Legend of Good Women, Metamorphoses, Memory.

A lo largo de su amplia producción, Geoffrey Chaucer construye una voz autoral dinámica, en perpetuo diálogo con la palabra autorizada de sus precedentes clásicos y medievales, y nos obliga por tanto a adentrarnos en una compleja trama en la que se dan cita sus modelos reverenciados con diversas tradiciones literarias y lingüísticas. Si a este panorama se añade la ingente producción crítica que siglos de erudición y comentario han cimentado alrededor de la obra del poeta inglés, el investigador contemporáneo encuentra que cada abordaje de los textos del poeta inglés constituye un verdadero desafío.

De las numerosas voces críticas que han enriquecido el contacto con su obra me han surgido algunas reflexiones a propósito del último poema onírico-visionario compuesto por Chaucer, su Legend of Good Women, datada alrededor de 1386 (con una revisión posterior de principios de la década siguiente). ${ }^{1}$ En este texto, uno más entre los que el poeta deja inacabados, Chaucer reelabora una variedad de fuentes literarias clásicas así como medievales que comprenden a Ovidio (el "propiamente dicho" y el moralizado, y tanto las Metamorfosis como las Heroidas), Virgilio, Estacio, Valerio Flaco, Dares, Guido delle Colonne, el Roman de la Rose, Vicente de Beauvais, Dante, Giovanni Boccaccio, Jean Froissart y Guillaume de Machaut, para componer un libro que, según plantea la ficción desarrollada en su prólogo, debe servir como penitencia para que el autor expíe su culpa por haber dejado mal parado al dios Amor en su traducción del Roman de la Rose y en Troilo y Criseida.

Este es el trasfondo que ha orientado en mi lectura de la obra de Chaucer; a partir de esa base, en este trabajo planteo volver sobre The Legend of Good Women para reconsiderar algunos de los matices que caracterizan

Recepción: 19 de abril de 2018 | Aprobación: 10 de julio de 2018 | Publicación: 05 de septiembre de 2019 
su relación con Ovidio. No es mi intención llevar a cabo un estudio de las fuentes, sino que mi propósito es el de destacar la forma en que Chaucer internaliza el modelo ovidiano en su texto a través de la selección de algunos de sus componentes y los convierte en principios productivos, siempre guiado por un criterio de imitación selectiva, parcial, que lo afilia a la vez que lo diferencia de la tradición. ${ }^{2}$

En The Legend of Good Women, así como en sus otros textos visionarios, Chaucer convierte la relación que establece con sus modelos literarios en un núcleo temático a partir del cual ficcionaliza las condiciones en que se genera y es recibido el poema. ${ }^{3}$ En el marco de dicho procedimiento se inscribe, bajo la forma de un intercambio de acusaciones y de defensas entre los personajes del prólogo, una reflexión sobre el impacto cultural de la labor del poeta como mediador entre la herencia literaria y su recepción en el presente. El juego se inicia con el reproche que el dios Amor dirige al narrador, acusándolo de haber ampliado los alcances de la literatura amorosa a través de la traducción y de haber habilitado, a partir de allí, la posibilidad de ejercitar lecturas sin mediaciones; la consecuencia es la difuminación de los límites entre las distintas clases de lectores definidas por sus posibilidades de acceso a la poesía cortés como bien simbólico y cultural que había sido, en principio, patrimonio distintivo de las aristocracias:

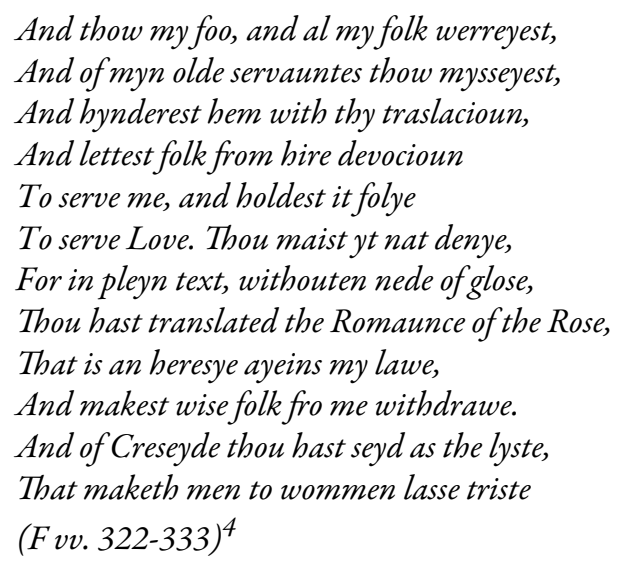

... y tú mi enemigo que censura a todos mis devotos y calumnia y molesta a todos mis antiguos sirvientes; con tu traducción manipulas a la gente para que no me sirva y sostienes que es una locura servir al Amor. No puedes negarlo porque has traducido El libro de la rosa a un texto sencillo, sin necesidad de glosarlo, lo cual es una herejía contra mis leyes; has hecho que la gente culta me abandone. De Criseida [...] has dicho lo que te ha dado la gana, lo que hace que los hombres confíen menos en las mujeres (137). ${ }^{5}$

Dejando de lado la discusión sobre las formas en que Chaucer ejerce la ironía en sus ficciones, la protesta del dios deja en evidencia las líneas rectoras que atraviesan su obra: el interés por la divulgación de materiales originalmente no escritos en inglés, la ampliación de horizontes literarios (que supone que la gente no necesariamente "culta" en los términos en que lo dice Amor tenga acceso a ellos), la renuencia a asignar significaciones alegóricas a sus textos (que hace innecesaria la glosa). Lo tradicional se abre así a la posibilidad de adquirir nuevos efectos.

En los inicios y en las conclusiones de los poemas oníricos de Chaucer siempre se encuentran los libros, y de manera recurrente entre esos libros se encuentra Ovidio, razón por la cual P. Boitani ha caracterizado el horizonte de estos poemas como persistentemente ovidiano y clásico:

Chaucer's dream poems begin with a book and end with a book, generally his own. His dreaming begins with Ovid's Metamorphoses and ends with Chaucer's own books. In this double pattern there is an extraordinary circularity and an equally staggering direct pointedness: when Chaucer dreams, a book inevitably produces another book. The 'old' book becomes 'new'. Ovid becomes Chaucer (44). ${ }^{6}$ 
Parafraseando esta última afirmación de Boitani, The Legend of Good Women es también, en más de un sentido, un relato de metamorfosis, no solamente porque Ovidio es invocado como uno de los móviles del proceso creativo, sino porque este motivo literario constituye un elemento rector en la percepción de la función que asumen los relatos particulares sobre las buenas mujeres en la estructura de la obra, y de la función de la propia obra en su contexto cultural. Es un poema en el que se lleva a cabo una metamorfosis que transfiere la autoridad clásica a la composición vernácula; a partir de dicha autorización, la narrativa en inglés medio puede reclamar una posición entre los artefactos que aseguran a futuro una memoria cultural compartida.

El proceso, sin embargo, no es lineal, y en el caso de The Legend of GoodWomen supone una dislocación del motivo de la metamorfosis. Sin dudas, uno de los rasgos que llaman la atención al recorrer las historias es la elisión del motivo allí donde resultaría más esperable: la Leyenda de Tisbe (vv. 706-923), por ejemplo, sigue de cerca el texto de Ovidio (Met. IV.55-166) pero, a pesar de la tendencia a expandir el relato con detalles de invención propia, Chaucer concluye la historia sin hacer referencia alguna a la metamorfosis en sí (la transformación de las moras en frutos oscuros). ${ }^{7}$

Asimismo, la Leyenda de Filomela (Met. VI.424-605) omite la venganza de las mujeres hacia Tereo y la metamorfosis de todos los personajes en aves, y simplemente concluye con una consideración del narrador: "The remenaunt is no charge for to telle, / For this is al and som" (vv. 2382-2383). ${ }^{8}$ En la Leyenda de Ariadna hay una rápida mención a la transformación de su diadema en constelación, pero no se incluyen detalles sobre las circunstancias que derivaron en ella:

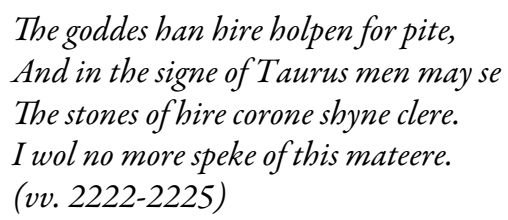

Los dioses la ayudaron por compasión y en el signo de Tauro la gente puede ver las piedras de su corona brillar claramente. No diré nada más sobre el tema (p. 174).

Nos encontramos, en principio, frente a una apropiación anómala de las Metamorfosis tanto en su vertiente clásica como medieval: no solamente se deja de lado la secuencia sobre la que descansa gran parte de la tensión que genera el relato, sino también se aparta de la profusa tradición de interpretación alegóricomoralizante a la que los textos de Ovidio dieron lugar durante toda la Edad Media al no arriesgar una conclusión normativa. Chaucer es, en términos de A. C. Spearing, un literalista: "Chaucer shows little interest in allegorical interpretation or hidden meanings. He is a literalist [...]. For Chaucer 'fable' usually means simply fiction, as opposed to 'storyal soth'” (159).?

No obstante, en The Legend of Good Women hay una metamorfosis narrada en el prólogo, que es la transformación de la reina Alcestis en margarita. El motivo es introducido por la pregunta que el dios Amor dirige al poeta: 
- ¿No tienes tú un libro que yace en tu cajón sobre la gran diosa, la reina Alcestis, que se convirtió en una margarita, ella, la que eligió morir por su esposo e ir al infierno también en lugar de él y Hércules la rescató y la sacó del infierno para alabarla de nuevo?

-Sí, ahora la reconozco -le dije-, es la buena de Alcestis, la margarita, el descanso de mi propio corazón (141).

Aunque se han propuesto algunas fuentes posibles, ${ }^{10}$ ninguna de ellas incluye la transformación del personaje en flor, y la procedencia de la historia central sigue siendo incierta. En realidad, la "buena mujer" del Prólogo, la dama a la que el sujeto adora y dedica sus servicios, y que termina revelándose como la reina Alcestis, no responde a modelos clásicos sino a la imagen de la margarita tal como fue plasmada en la poesía vernácula medieval: el Roman de la Rose, en primer término, pero también la obra de poetas franceses cronológicamente más cercanos a Chaucer que elaboran el tema: Jean Froissart con su Dit de la marguerite, el Paradis d'Amour de Eustace Deschamps, los poemas de amor de Guillaume de Machaut. Estos escritores, que realizan una muy libre adaptación de la literatura ovidiana, ${ }^{11}$ coinciden en su propósito de hacer que la tradición en lengua vulgar quede inscripta en pie de igualdad con los "antiguos libros". Chaucer no solo sigue estos modelos en su imitación de la producción vernácula que le resulta más cara, sino que deriva de ellos la autoridad para hacer propios los procedimientos y los motivos literarios (clásicos o no) que le permiten dar forma a su universo ficcional; es decir, asume frente a los auctores las actitudes que otros escritores de avanzada habían adoptado poco antes en el ámbito francófono; por cierto, en la Inglaterra del último cuarto del siglo XIV este gesto implica una profunda innovación a través de la cual la literatura en inglés medio se nutre de la autoridad alcanzada por otros experimentos en lengua vulgar.

El tratamiento de la figura de la margarita, luego superpuesta a la dama Alcestis, centro del goce del sujeto en el marco primaveral de su relato, se destaca como elemento novedoso dentro de la invocación del tópico de la primavera, recurrente en los poemas oníricos de Chaucer (y vale recordar también su inclusión en el inicio del Prólogo General de los Cuentos de Canterbury); ${ }^{12}$ el escenario primaveral suele ocupar un espacio liminal, pues está inserto en las situaciones de pasaje que el sujeto transita entre la experiencia del mundo real y el ámbito del sueño. En todos los casos queda asociado con la noción de productividad, no solo por el simbolismo propio de la estación primaveral, sino también porque el personaje (que es también un poeta) deja provisoriamente de lado su frenética actividad lectora para pasar al sueño; el sueño implica una vivencia transformadora, que hace que la masa amorfa de sus lecturas, una vez mediatizada por la experiencia onírica, derive en la escritura de un libro.

Estas situaciones liminales, enmarcantes, ofrecen un entramado que Chaucer hace más complejo y comenta con los propios textos, que van añadiendo estratos al problema central de la relación entre la escritura propia y la tradición con la que dialoga. La voz del poeta no se limita a construir un sujeto pseudoautobiográfico que comunica su experiencia sino que trasmite el punto de vista de un comentador que reflexiona sobre su papel como lector/escritor. En la versión F del Prólogo de The Legend of Good Women el narrador declara: 
Y en cuanto a mí, aunque yo sé muy poco, disfruto leyendo libros y me fío y creo en ellos. Y en mi corazón los venero con tal vehemencia que no hay diversión que me haga apartarme de mis libros, excepto quizás en vacaciones, cuando llega el mes de mayo y oigo a los pájaros cantar y las flores empiezan a florecer en primavera: jadiós a mis libros y a mi devoción! (131).

El escenario primaveral se convierte, en principio, en el escenario de la amorosa visione que tiene como centro a la venerada margarita, fuente de inspiración poética (según el modelo del Dit de la marguerite de Machaut), a la vez objeto del sueño en que cae el sujeto:

\section{Ifel on slepe within an houre or twoo. \\ Me mette how I lay in the medewe thoo, \\ To seen this flour that I so love and drede \\ (Fvv. 209-211)}

Cuando estaba acostado y tenía mis ojos cerrados, me dormí durante una hora o dos. Entonces, me pareció que yacía en un prado para ver la flor que tanto amo y reverencio (135).

La aparición del dios Amor y su reproche al poeta por haber maltratado a las mujeres en su obra da lugar poco más adelante a la defensa que lleva adelante Alcestis, que incluye la enumeración de los textos escritos por de Chaucer:

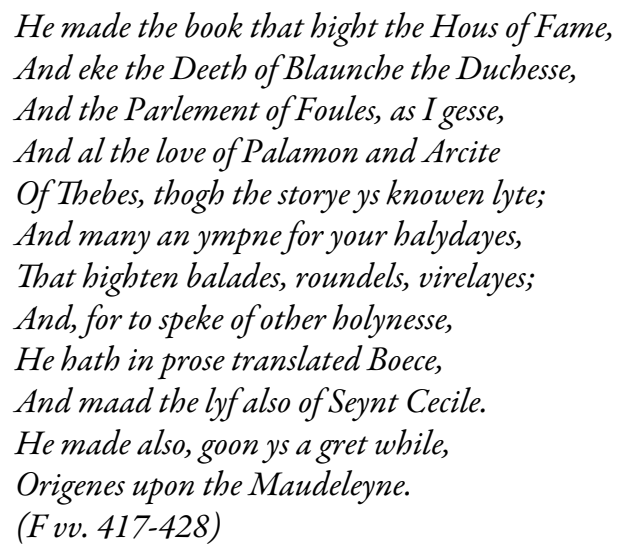

Él ha escrito un libro que se titula La Casa de la Fama y también la Muerte de la duquesa Blanca, e imagino que El Parlamento de las aves, y todo sobre el amor de Palemón y de Arquitas de Tebas, aunque la historia es poco conocida; y muchos himnos, que se llamaban baladas, para los días en los que se celebra tu fiesta, rondeles y virolais; y para hablar de otra festividad tradujo en prosa a Boecio, escribió la Vida de Santa Cecilia y también escribió los Orígenes de la Magdalena, que le llevó mucho tiempo (139). ${ }^{13}$

En este marco, los libros de Chaucer comparten el carácter generativo propio del escenario primaveral, pues son la razón por la cual se encomienda al sujeto la composición de un nuevo texto:

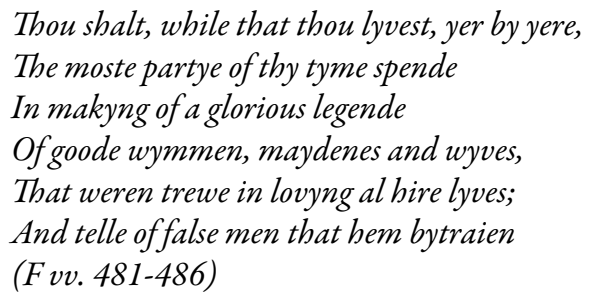

Mientras vivas, año tras año, pasarás la mayor parte del tiempo escribiendo una gloriosa Leyenda de las buenas mujeres, solteras y casadas, que fueron fieles en el amor durante toda su vida; y tratarás de los hombres falsos que las traicionaron (140). 
Por el mandato de la reina la escritura no solo queda atada al ciclo vital del escritor, sino que queda identificada con una función memorial que define su orientación en The Legend of Good Women. No es casual que el prólogo incluya numerosos términos que remiten al campo semántico de la memoria y de la actividad intelectual, como ha señalado Florence Percival: understond (v.470), holden ("considera", v. 479), ${ }^{14}$ que junto con la referencia al libro sobre Alceste que atesora el poeta pone en relieve la función metaliteraria del pasaje:

The reference to the book about Alceste which lies in the poet's "cheste" appears to be literal, but is probably also a metaphorical allusion to the poet's memory, commonly thought of as a storage box or treasure chest, and is a clear signal of the epistemological dimensions of the scene. ${ }^{15}$

No se trata aquí de aleccionar al narrador para que cambie sus actitudes frente al amor (el sujeto chauceriano es, en este sentido, un caso perdido $)^{16}$ sino para que ponga en marcha su condición de productor y dedique sus esfuerzos a una escritura que asegure la conversión del conocimiento en memoria, su pasaje de la esfera individual a la cultural: "And thogh the lesteth nat a lovere be, / Spek wel of love; this penaunce yeve I thee" (vv. 480-481). ${ }^{17}$ Es así que la escritura en tanto dispositivo que permite poner en marcha los mecanismos del conocimiento y de la memoria en nuevas situaciones (verdadera "llave del recuerdo") suele estar tematizada en la obra de Chaucer a través de un repertorio de imágenes familiar para quien haya recorrido sus textos. Una de esas "llaves" en The Legend of Good Women es la metamorfosis en estrella o constelación. Dice el narrador:

Now knowe I hire. And is this good Alceste,
The dayesie, and myn owene hertes reste?
Now fele I weel the goodnesse of this wyf,
That both aftir hir deth and in hir lyf
Hir grete bounte doubleth hire renoun.
Wel hath she quyt me myn affeccioun
That I have to hire flour, the dayesye.
No wonder ys thogh Jove hire stellyfye,
As telleth Agaton, for hire goodnesse!
(Fvv. 518-526)

-Sí, ahora la reconozco [...], es la buena de Alcestis, la margarita, el descanso de mi propio corazón. Ahora siento bien la bondad de esta esposa que tanto después de su muerte como en su vida duplicó su bondad a su fama. Bien ha recompensado el afecto que yo le tengo a su flor, la margarita. ¡No es maravilla entonces que Jove la haya convertido en estrella como lo cuenta Agatón, por su bondad! (p. 141; las itálicas me pertenecen). ${ }^{19}$

En el universo de la ficción chauceriana el catasterismo, una forma de escritura sobre los cielos, remite a idea de que el beneficiario de la metamorfosis adquiere desde su perspectiva privilegiada en las alturas una forma de conocimiento superior que le permite valorar y mensurar adecuadamente los fenómenos del mundo. ${ }^{20}$ Frente a la fijeza que supone este punto de vista autorizado, Chaucer-narrador se niega a adoptar la posición de objeto de contemplación y reivindica para sí el espacio de la agencia, de la intervención, del perpetuo "hacerse". Para quienes como él optan por el mundo sublunar, al igual que las historias, las pinturas y otros objetos culturales (esculturas, vitrales, inscripciones monumentales) que pueblan sus poemas, la inscripción en los cielos constituye una oportunidad más de poner en marcha los mecanismos de la memoria, y por ende de la escritura.

Con este marco de ideas, es posible pensar que los relatos de buenas mujeres integrados en el libro son absorbidos por el campo semántico de la memoria a partir del motivo de la metamorfosis (en flor, en estrella) del prólogo, e incluso quedan subsumidos en este motivo los relatos que en principio no tienen que ver con metamorfosis alguna (tal como los de Cleopatra o Lucrecia, que corresponden al campo de lo histórico). Sin embargo, The Legend of Good Women sería un libro imposible si el poeta llevara hasta las últimas 
consecuencias el mandato de dedicar toda su vida a la escritura (vida y escritura tendrían, hipotéticamente, la misma duración). Es el propio dios Amor el que da la solución y hace explícito el principio que permite que la memoria no termine siendo una empresa inviable: el pasado no es aprehensible en su totalidad, se ofrece en fragmentos y su recuperación, en definitiva, supone siempre alguna clase de reinterpretación o de glosa. Esta situación está explícitamente tematizada en el marco de The Book of the Duchess y The House of Fame, en que aparecen escenas de las historia troyana y del Roman de la Rose como una serie de escenas no-continuas que, sin embargo, están disponibles como repositorio que permite activar una memoria más completa, aunque quizá nunca total. ${ }^{21} \mathrm{El}$ dios Amor condensa el principio de que la escritura no puede abarcar exhaustivamente la memoria de una sociedad en su declaración "I wot wel that thou maist nat al yt ryme" (v. 570), ${ }^{22}$ que continúa:

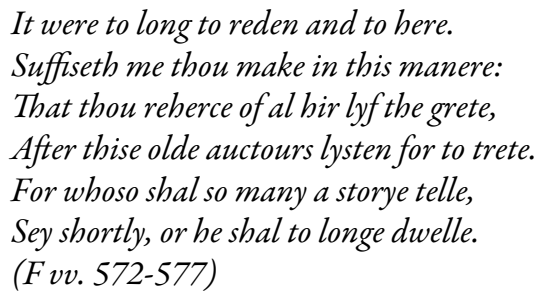

[...] sería demasiado largo leerlo y oírlo. Me basta con que lo hagas de esta forma: que realces todo lo sustancial de su vida y de acuerdo a como los escritores antiguos quisieron que se tratara. Y que quien cuente tantas historias sea breve, o se demorará demasiado (142; las itálicas me pertenecen). ${ }^{23}$

La brevedad en el discurso y la selección de lo esencial en el contenido se establecen como los principios compositivos explicitados con mayor frecuencia a lo largo del libro; a partir de ellos quedan patentes las diferencias que separan la escritura de Chaucer de la de sus modelos, siempre más propensos a demorarse en el relato:

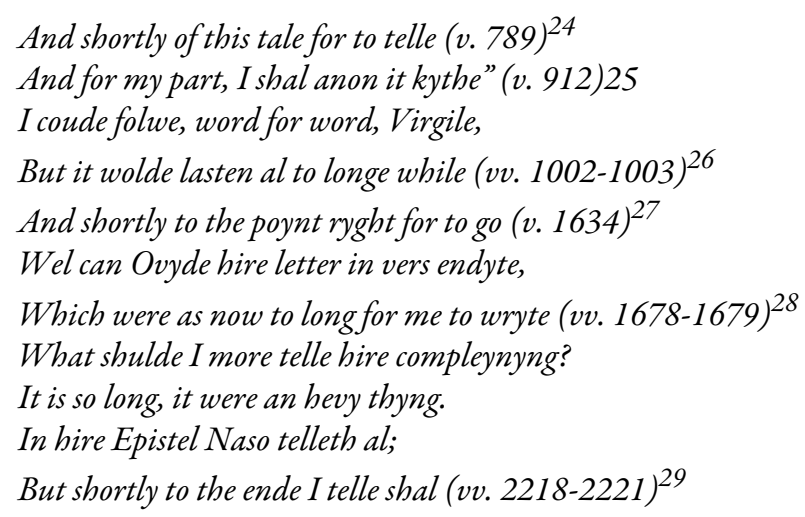

Se ha sugerido cierto paralelo entre el proyecto narrativo de The Legend of Good Women y el Monk's Tale, uno de los Cuentos de Canterbury. ${ }^{30}$ En dicho cuento, que es considerado el más dantesco dentro de la colección, Chaucer ensaya una forma de micro-relatos que, sobre la base de la recurrencia de situaciones desdichadas apunta a reforzar la percepción del patrón de elevación y caída propio del modo trágico tal como era concebido en su época, de acuerdo con una fuerte impronta boeciana que identifica lo trágico con la noción de "tragedia de fortuna" ${ }^{31}$ En realidad, el cuento ofrece una "poética del caso", con una serie potencialmente infinita de historias breves que se extienden desde la Antigüedad hasta llegar casi al presente, lo que justificaría que el cuento no tenga un cierre formal sino que termine abruptamente en el momento en que el Monje es interrumpido por el Caballero: 


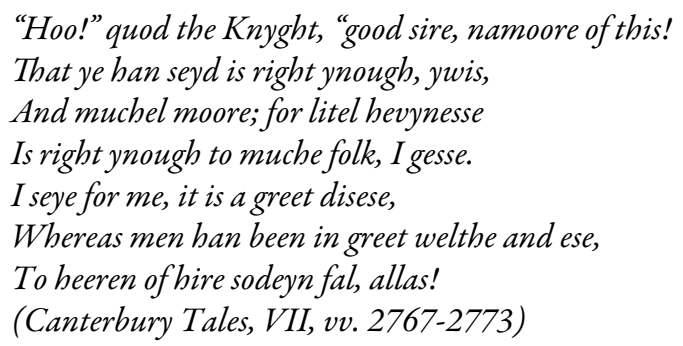

-¡Oh! -exclamó el Caballero- ¡Buen señor, no más de esto! Lo que usted ha dicho es mucho más que suficiente; pues entiendo que para mucha gente un poco de desgracia es ya bastante. Para mí es triste oír la repentina caída de la gente que vivió en riqueza y comodidad. ¡Vaya! (p. 481).

Más allá de las diferencias en la perspectiva, más cercana al carácter elegíaco de las Heroidas que al modo trágico, apelar a la cercanía con The Monk's Tale puede resultar revelador: ambos relatos responden a una forma deliberadamente condensada, incluso con sus diferencias de extensión y de tratamiento. En los dos casos, se trata de series de historias que reiteran un patrón (de engaño y lamento en un caso, de ascenso y caída en el otro) y que no tienen una conclusión, simplemente son terminadas. Podría pensarse, además, que ambos relatos se proponen como inscripciones, como un repositorio de "memoria narrativa y cultural" que evoca, desde lo fragmentario, una memoria completa que puede ser recuperada por el receptor, ${ }^{32}$ lo cual justifica las numerosas recomendaciones de leer a los auctores si se desea conocer más, como la que se da en el cierre de la Leyenda de Ariadna, citada más arriba. Estas historias no se proponen ser exhaustivas, tampoco completar o reiterar, ni mucho menos reemplazar lo que los grandes autores del pasado han legado a la posteridad; se presentan, en cambio, como parte de un proceso no interrumpido de actualización de dicha herencia, que conforme transcurre el tiempo, requiere de nuevos instrumentos que aseguren su continuidad.

En este sentido, los libros antiguos son claves en el mantenimiento de esta memoria: "And yf that olde bokes were aweye, / Yloren were of remembraunce the keye” (vv. 25-26). ${ }^{33}$ La propia obra de Chaucer no solo se concibe como un aporte específico dentro de esa empresa trascendente y supraindividual, sino que reflexiona sobre las condiciones en que este esfuerzo se lleva adelante a través del contacto de generaciones de lectores con los libros, viejos y nuevos. El curioso manejo de las metamorfosis en The Legend of Good Women puede ser considerado, en definitiva, como uno más de los elementos que permiten comprender cómo el propio texto se transforma en memoria, en una renovada "llave del recuerdo".

\section{Notas}

1 M. C. E. Shaner destaca en la breve nota introductoria que acompaña su edición del poema que se trata de un producto de la madurez artística de Chaucer, escrito no mucho después de Troilo y Criseida y antes (o durante) la composición de los Cuentos de Canterbury; véase The Legend of Good Women, ed. de M. C. E. Shaner en L. D. Benson (ed. gral.), The Riverside Chaucer, Oxford, Houghton Mifflin - Oxford University Press, 1987, 587-630. Es difícil proporcionar una datación precisa para las leyendas, aparentemente escritas antes que el Prólogo, que a su vez fue reelaborado y sobrevive en dos versiones ( F y G, esta última solo en el manuscrito de la Cambridge University Library Gg 4.27). La crítica ha destacado en F la presencia una posible alusión a la reina Ana, por lo cual debió haber sido redactado en algún momento entre su llegada a Inglaterra desde Bohemia a principios de 1382 y su muerte en junio de 1394. Más datos sobre la datación de The Legend of Good Women pueden consultarse en R. Rossignol, Critical Companion to Chaucer. A Literary Reference to His Life and Work, New York, Facts on File, 2006, 156-158.

2 La cuestión de la transferencia de autoridad del latín a la producción vernácula así como su importancia en los momentos fundacionales de las distintas tradiciones literarias durante la Edad Media ha sido objeto de numerosos estudios en los que se ha llamado la atención sobre la variedad de actitudes frente a los modelos, que pueden comprender desde la traducción directa y fiel hasta la reelaboración casi completa; véase D. Kelly, "Translatio Studii: Translation, Adaptation, and Allegory in Medieval French Literature", Philological Quarterly 57, 1978, 287-310. P. Damian-Grint ("Translation as Enarratio and Hermeneutic Theory in Twelfth-Century Vernacular Learned Literature”, Neophilologus 83, 1999, 349-367) destaca que la interpretación y adaptación de los materiales clásicos son parte inherente del proceso de 
transferencia del ámbito clásico al vernáculo, de modo que se justifica pensar dicha transferencia como una apropiación: "[This appropriation] did more than simply provide a justification for the translation of learned texts, however. It also provided a hermeneutic that presented vernacular texts as having an auctoritas similar to that of their Latin originals, thus opening the way for the concept of vernacular literature which was original but also authoritative" (349). Las observaciones de Grint, aunque centradas en el momento de afirmación de la literatura francesa en el siglo XII, resultan válidas para reflexionar acerca de la consagración de otras literaturas vernáculas durante los siglos XIII y XIV.

3 Se trata de un procedimiento recurrente que supone una fuerte conciencia metaliteraria compartida por el autor y sus lectores. Analizo este aspecto con detalle en mi estudio "Chaucer y el género de las visiones oníricas", en A. Basarte y L. Cordo Russo (comps.), Géneros literarios medievales, Buenos Aires, EUDEBA, 2019, 213-230.

4 Cito el texto en inglés medio según la edición de M. C. E. Shaner en L. D. Benson (ed. gral.), The Riverside Chaucer, Oxford, Houghton Mifflin - Oxford University Press, 1987, 587-630.

5 Para el texto en español, sigo la traducción de J. L. Serrano Reyes en El Parlamento de las aves y otras visiones del sueño, Madrid, Siruela, 2005, 129-184. Ocasionalmente, cuando considero que la traducción es dudosa, introduzco correcciones propias sobre las que advierto en nota al pie.

6 P. Boitani, "Old Books Brought to Life in Dreams: the Book of the Duchess, the House of Fame, the Parliament of Fowls", en P. Boitani y J. Mann (eds.), The Cambridge Chaucer Companion, Cambridge, Cambridge University Press, 1986, 39-57.

7 Para una consideración general de las transformaciones que Chaucer realiza de los textos de Ovidio remito a las pormenorizadas notas explicativas de M. C. E. Shaner y A. S G. Edwards a cada leyenda en The Riverside Chaucer, Oxford, Houghton Mifflin - Oxford University Press, 1987.

8 "El resto de la historia no viene a cuento relatarla pero este es el resumen" (177).

9 A. C. Spearing, "The Canterbury Tales IV: Exemplum and Fable”, en P. Boitani y J. Mann (eds.), The Cambridge Chaucer Companion, Cambridge, Cambridge University Press, 1986, 159-177. "Storyal soth" equivale a "verdad histórica".

10 Entre ellas, se han propuesto las Fábulas de Higinio y la Genealogia deorum de Boccaccio. F. Percival se detiene en la consideración de las distintas fuentes del pasaje, tanto antiguas como medievales en Chaucer's Legendary Women, Cambridge, Cambridge University Press, 1998, esp. 21-58.

11 Percival, Chaucer's Legendary Women, Cambridge, Cambridge University Press, 1998, 23. Sobre la imagen margarita, su significación y sus usos poéticos en el siglo XIV, véase J. I. Wimsatt, The Marguerite Poetry of Guillaume de Machaut, Chapel Hill, University of North Carolina Press, 1970.

12 "Whan that Aprill with his shoures soothe / The droghte of March hath perced to the roote..." (Canterbury Tales, General Prologue, vv. 1-2); ed. de L. Benson en The Riverside Chaucer, Oxford, Houghton Mifflin - Oxford University Press, 1987, 3-328. (“Cuando las suaves lluvias del mes de abril penetran hasta las raíces de la sequedad de marzo...”; trad. de los Cuentos de Canterbury de J. L. Serrano Reyes y A. R. León Sendra, Madrid, Gredos, 2004, 65).

13 Por razones de rigor, transcribo literalmente la traducción de Serrano Reyes, aunque discrepo de la interpretación que ofrece de los vv. 427-428, en la que se ha deslizado un evidente error: el texto inglés dice "También hizo ["tradujo"] hace ya mucho tiempo, a Orígenes sobre la Magdalena”. Se trata de una referencia a una traducción de Chaucer, perdida, de la homilía De Maria Magdalena del Pseudo-Orígenes; véase la nota de Shaner al v. 428 en The Riverside Chaucer, Oxford, Houghton Mifflin - Oxford University Press, 1987, 1065.

14 F. Percival, Chaucer's Legendary Women, Cambridge, Cambridge University Press, 1998, 52.

15 F. Percival, Chaucer's Legendary Women, 52-53.

16 Efectivamente, a lo largo de su producción poética (no solamente en los poemas oníricos), Chaucer construye un sujeto que invariablemente se caracteriza por su alienación respecto de las pasiones amorosas, por un conocimiento del amor siempre externo, mediatizado por sus profusas lecturas. Recuérdese el reproche que el águila le dirige al poeta en los vv. 613-660 de The House of Fame (en L. D. Benson, ed. gral., The Riverside Chaucer, Oxford, Houghton Mifflin - Oxford University Press, 1987, 347-373).

17 “...y aunque tú, desgraciadamente, no eres amante, habla sobre el amor. Esta penitencia te impongo" (140).

18 Se ha especulado sobre la identidad de Agatón: puede tratarse del dramaturgo griego mencionado en Dante, Purg., XXII,107, o del personaje del Symposium de Platón. Sin embargo, el catasterismo de Alcestis no aparece allí, y su procedencia sigue siendo incierta. Véase la nota a los vv. 525-526 en The Riverside Chaucer, 1065.

19 Incluyo (marcada en itálicas) mi propia traducción del v. 525 porque discrepo de la traducción propuesta por Serrano Reyes, en la que la metamorfosis de Alcestis resulta atribuida a una segunda persona (el dios Amor) y no a Jove, como claramente se ve en el texto inglés. La traducción de Serrano Reyes dice "No entiendo cómo tu poder la convirtió en una estrella” (p. 141).

20 En este punto vale la pena recordar el tratamiento cómico de esta situación en el Libro II de The House of Fame, en que el narrador es transportado a las alturas por el águila dorada: "O God, thoughte I, that madeste kynde, / Shal I noon other weyes dye? / Wher Joves wol me stellyfye, / Or what thing may this sygnifye?” (vv. 584-587 (“iOh, Dios, que has creado la Naturaleza!, ¿no hay otra forma de morir? ¿Me convertirá Júpiter en estrella o qué puede significar esto?”, p. 86). 
21 He realizado una aproximación a algunas de las implicancias de la recuperación parcial del pasado clásico por parte del sujeto narrador a partir de referencias a la historia de Troya en "Troya historiada en The Book of the Duchess y The House of Fame", en: V Jornadas de Estudios Clásicos y Medievales "Diálogos Culturales". La Plata, 5-7 de octubre de 2011, disponible en http://jornadasecym.fahce.unlp.edu.ar/. Señalé allí la importancia de la conexión con los auctores como elemento constitutivo de una poética que más que se inclinarse por las interpretaciones alegórico-normativas, apunta a reforzar en el lector la conciencia sobre la relación genética que la herencia clásica, convertida en una verdadera memoria de la cultura, guarda respecto de la propia producción, y en realidad respecto de toda producción verbal.

22 "Sé bien que no puedes poner todo en rimas"; traducción propia del pasaje.

23 Incluyo mi propia traducción de los vv. 576-577 (marcada en itálicas) porque no estoy de acuerdo con la traducción que en este punto ofrece Serrano Reyes, que dice: "y quien cuenta tantas historias brevemente, le digo que las explique largamente" (142).

24 "Para abreviar esta historia" (146).

25 "Yo, por mi parte, no revelaré más" (traducción propia).

26 "Virgilio, podría seguirte palabra por palabra, pero sería demasiado largo" (150).

27 "Para ir rápidamente al grano...” (162).

28 "Ovidio termina completamente en verso su carta, que ahora sería demasiado larga para mí" (163).

29 “¿Para qué voy a contar más sobre su lamento? Sería muy largo, sería muy pesado. Naso lo cuenta todo en sus Heroidas. Pero para terminar, lo contaré brevemente" (174; se refiere al lamento de Ariadna).

30 Véase al respecto la nota introductoria de L. Benson sobre este cuento en The Riverside Chaucer, 17.

31 En el exordio de su cuento, el personaje declara: "I wol biwaille in manere of tregedie / The harm of hem that stoode in heigh degree, / And fillen so that ther nas no remedie / To brynge hem out of hir adversitee. / For certein, whan that Fortune list to flee, / Ther may no man the cours of hire withholde. / Lat no man truste on blynd prosperitee; / Be war by thise ensamples trewe and olde" (Canterbury Tales, VII, vv. 1991-1998). ("Quiero lamentarme, a modo de tragedia, del dolor de aquellos que estuvieron en una alta posición y cayeron de tal manera que no hubo remedio para sacarlos de su adversidad. Pues cuando a la Fortuna le place huir, no hay nadie que pueda parar su curso. Que nadie confíe en la ciega prosperidad; estad avisados por estos ejemplos antiguos y auténticos”, Cuentos de Canterbury, 460).

32 La frase es de S. Powrie, "Alain de Lille's Anticlaudianus as Intertext in Chaucer's House of Fame”, The Chaucer Review, 44, 2010, 248. A propósito de las estrategias de condensación y fragmentación en Chaucer, Powrie propone: "Each structure functions as a kind of storage house for narrative and so appears to be a guarantor of narrative preservation or literary dissemination; however, none of these structures can guarantee fidelity to the author's original design. The narrative will be transformed as it is recorded, remembered, and retold" (259).

33 "Y si esos libros antiguos no existieran, estaría perdida la llave del recuerdo" (131). 